\title{
Diferentes, não desiguais: a questão de gênero na escola
}

\author{
Suely Aparecida do Nascimento Mascarenhas' (D \\ Adan Renê Pereira da Silva' (D)
}

LINS, B. A.; MACHADO, B. F.; ESCOURA, M. Diferentes, não desiguais: a questão de gênero na escola. São Paulo: Reviravolta, 2016. 142p.

“Como a gente pode fazer para mudar isso, professor?". Essa foi a pergunta que escutei de uma entrevistada - também docente - ao término de uma entrevista que visava coletar dados para uma pesquisa sobre gênero e diversidade sexual na escola. A reflexividade acabou conduzindo-nos ao livro objeto desta resenha.

"Diferentes, não desiguais" divide-se em oito capítulos e contém ricos apêndice e glossário. Beatriz Lins, Bernardo Machado e Michele Escoura escrevem da posição de doutorandos. No momento da publicação da obra, Beatriz Lins e Bernardo Machado eram doutorandos em antropologia social pela Universidade de São Paulo (USP), e Michele Escoura, doutoranda em ciências sociais pela Universidade Estadual de Campinas (UNICAMP). Talvez daí a tônica culturalista da argumentação, que aparece logo no primeiro capítulo, quando gênero é definido como um dispositivo cultural, construído historicamente, demarcando diferenças pressupostas entre meninos e meninas. Essa demarcação já é introjetada no próprio ambiente escolar: há atividades "de meninos" e "de meninas" (desde filas escolares até esportes "femininos e masculinos" nas aulas de educação física).

Além de definir gênero, o primeiro capítulo problematiza ideias por trás da construção do masculino e do feminino e das relações de gênero desenvolvidas. Ao discutirem como a escola constrói expectativas nas crianças, os autores afirmam que se podem inferir desigualdades e hierarquias criadas culturalmente pela socialização que irão se imiscuir na estrutura de poder da sociedade. Nesse sentido, ao internalizar regras de gênero propostas pela escola, incutem-se noções de "certo" e "errado" nas subjetividades, ancoradas em pretensas noções biológicas. Essa acriticidade do ensino de papéis sociais não pode tornar-se lugar comum.

Para gestar uma escola plural, crítica e transformadora, algumas ações são sugeridas. Entre elas estão o uso de uma linguagem inclusiva - aquela que reconhece meninos, meninas e outras pessoas que não se enquadrem nesse binarismo - e a recusa da adoção de estereótipos de gênero. É preciso problematizar naturalizações,

'Universidade Federal do Amazonas, Manaus, AM, Brasil. 
sendo um bom instrumento o conceito de "relações de gênero", o qual desuniversaliza masculino/feminino e ajuda a entender diferenças, problematizando desigualdades.

O capítulo dois amplia as reflexões sobre gênero, destacando a importância do surgimento do termo para a teoria social. Margaret Mead, por exemplo, mostrou como a cultura medeia o que homem e mulher fazem e as pluralidades do modo de fazê-lo. Historiando as três ondas do movimento feminista, apresentam-se personalidades brasileiras que construíram o movimento, como Lélia Gonzalez, uma das principais militantes do movimento feminista negro.

O destaque fica por conta da terceira onda, a qual trouxe produções como a de Judith Butler, propiciou a aproximação do feminismo com o movimento LGBT, abriu espaço para o protagonismo de mulheres negras questionando o racismo entre mulheres brancas e negras, problematizou a desigualdade entre homens e mulheres negros e negras e, ainda, pautou o tema da interseccionalidade, mostrando que diferentes situações de desigualdade social interpenetram-se entre si.

Já o terceiro capítulo trata dos direitos das mulheres, falando dos principais instrumentos legais (Lei Maria da Penha e tratados internacionais dos quais o Brasil se fez signatário) e o abismo existente entre o formalismo da lei e sua execução. Esse momento propedêutico dá margem para a efetiva aproximação entre a questão de gênero e o espaço escolar, assunto do quarto capítulo.

Tematizando a violência ligada ao poder, autoras e autor expõem modos pelas quais ela pode acontecer e como afeta a população LGBT, especialmente por pessoas desse grupo quebrarem expectativas e estereótipos de gênero, tornando-os/as alvo fácil de quem não aceita outros modos de expressão que não a cisheteronormatividade. Ao questionar a culpabilização da vítima e formas contemporâneas de violência, como a "pornografia de vingança", há um referencial teórico imprescindível para quem almeja um debate sério sobre uma escola plural e menos ameaçadora.

Entendida a importância da escola, é hora de aceitar o convite para falar de sexualidade, tema então tratado no Capítulo 5 . Por intermédio do levantamento feito pelo Grupo Gay da Bahia (2014), percebe-se que o Brasil é o país que mais mata LGBT no mundo. É necessário dar visibilidade a essas pessoas, mostrando que nem todos se adequam à matriz de gênero e que isso não é um problema. Também é importante entender o que significa cada termo desse universo e como a violência é produzida contra esse público.

Lins, Machado e Escoura também desmistificam, ainda no Capítulo 5, como toda a luta do movimento LGBT não tem relação com "privilégios", e sim com equidade. Apresentam possibilidades para uma escola diversa, entre elas: formação continuada de professoras/es, gestoras/es e toda a equipe técnica no tocante ao tema gênero; atenção para piadas, acusações, fofocas e situações constrangedoras que envolvam pessoas LGBT, mesmo que não haja na escola algum/a estudante autoidentificado/a como tal.

À página 76, um eco é fornecido à pergunta que inicia esta resenha: “[...] a diversidade de identidades de gênero é também uma questão que pode gerar muitas dúvidas e inseguranças em educadoras/es comprometidos com a construção de uma escola inclusiva”. É necessário agir cotidianamente para gerar espaços acolhedores a pessoas LGBT, e algumas ações pontuais são elencadas, entre elas: verificar, no 
estado/município em que se localiza a escola, os mecanismos de adoção do nome social na matrícula escolar para travestis e transexuais não serem constrangidos; participação de toda a equipe escolar nas formações específicas sobre gênero; pesquisas, rodas de conversa, debates, palestras e mediações de conflitos que tratem de gênero devem compor o planejamento anual em todas as disciplinas e ações para superação das desigualdades de gênero devem ser pensadas (constando no projeto político-pedagógico).

Tais possibilidades de intervenção não serão suficientes sem a ajuda de outros grupos sociais, entre eles a família. É no próximo capítulo que esse ponto é levantado, de forma reflexiva: O que a família tem a ver com isso? Lins, Machado e Escoura conduzem o/a leitor/a a um "passeio" por mudanças histórico-culturais que ajudam a desfazer preconceitos (como o de que deve haver um único modelo de família). Uma noção a ser ressignificada é a de "família desestruturada", posto que a "estruturada" (família que mora em um bom bairro, com carro, comida e casa confortável) é um ideal que passa longe da realidade de milhões de pessoas. Para defender esse ponto, é evocada nossa herança escravocrata, colonizada e genocida.

Mas esse não é único problema. Há "Outras diferenças", Capítulo 7, geradoras de mais desigualdades. Entram em jogo marcadores sociais da diferença, como classe, cor e, obviamente, gênero. Esses marcadores geram desigualdades no acesso a direitos e oportunidades (educação, renda, trabalho, saúde etc). $\mathrm{O}$ argumento é confirmado quando se analisam dados do Instituto Brasileiro de Geografia e Estatística (IBGE), os quais mostram que as diferenças transformadas em desigualdades seguem marcando pessoas, na presente e nas futuras gerações.

O último capítulo, "Últimas considerações", traz algumas ponderações levando em conta o exposto. Questiona o tipo de escola que queremos, porque isso impacta diretamente o modo como ela trabalhará desigualdades de gênero e combaterá as injustiças, violências, discriminações e marginalizações. Gênero é um instrumento útil como categoria analítica, pois nomeia o/a "diferente", e "[...] Nomear é, talvez, o primeiro passo para pensar e, então, transformar” (p. 102).

A obra apresenta outros pontos que valem a reflexão, como o apêndice instigador, com sugestões de trabalho para toda a equipe escolar. As sugestões versam sobre como desnaturalizar diferenças sociais, mobilizar a comunidade escolar e como realizar atividades sem investir nas divisões por gênero nem reiterá-las. Também há sugestões de materiais audiovisuais baseadas na pesquisa de Michele Escoura, uma das autoras, a qual concluiu que estereótipos de gênero influenciam a construção da autoimagem de discentes. A obra pensa, então, como alternativa, em filmes e livros que desconstroem padrões socialmente concebidos, ajudando a visibilizar outros modos de ser e de existir no mundo que contemplem as minorias sociais.

Finalizando a obra, um útil glossário que fornece, didaticamente, definições sobre termos que ajudam a discutir gênero, como "heteronormatividade", "feminicídio", "generificar". As definições são contextualizadas e em linguagem simples.

Panoramicamente, os comentários que podemos tecer sobre a obra são laudatórios. Na esteira de trabalhos culturalistas e pós-estruturalistas, o livro ajuda a fundamentar o trabalho com gênero na escola, apresentando sugestões concretas. O tom utilizado o torna inteligível até mesmo a quem não possui maior apro- 
fundamento no assunto. Profissionais que trabalham na área da educação (não só docentes) encontrarão em Diferentes: não desiguais estratégias e embasamento para um adequado debate científico. Por fim, parte da sociedade que precisa entender de fato o que é gênero terá um valioso instrumento para, eticamente, acolher e entender a diversidade humana.

\section{REFERÊNCIA}

LINS, B. A.; MACHADO, B. F; ESCOURA, M. Diferentes, não desiguais: a questão de gênero na escola. São Paulo: Reviravolta, 2016.

\section{SOBRE OS AUTORES}

Suely Aparecida do Nascimento Mascarenhas é doutora em diagnóstico e avaliação educativa-psicopedagogia pela Universidade da Coruña (Espanha). Professora da Universidade Federal do Amazonas (UFAM).

E-mail: suelymascarenhas1@gmail.com

Adan Renê Pereira da Silva é doutorando em educação pela Universidade Federal do Amazonas (UFAM).

E-mail: adansilva.1@hotmail.com

Recebido em 8 de junbo de 2019 Aprovado em 3 de outubro de 2019 